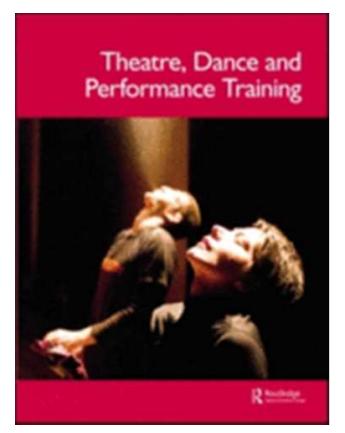

\title{
The Italic I - A 16 Stage Lexicon on the Arc of Falling
}

\begin{tabular}{|r|l|}
\hline Journal: & Theatre, Dance and Performance Training \\
\hline Manuscript ID & Draft \\
\hline Manuscript Type: & Special Issue Article \\
\hline Date Submitted by the Author: & n/a \\
\hline Complete List of Authors: & Cocker, Emma; Nottingham Trent University, Fine Art \\
\hline Keywords: & Falling, conversation, collaboration, exercise (askesis), performance writing \\
\hline & \\
\hline
\end{tabular}

SCHOLARONE $^{\text {m }}$

Manuscripts 


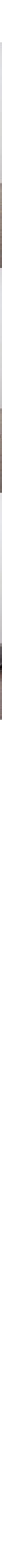




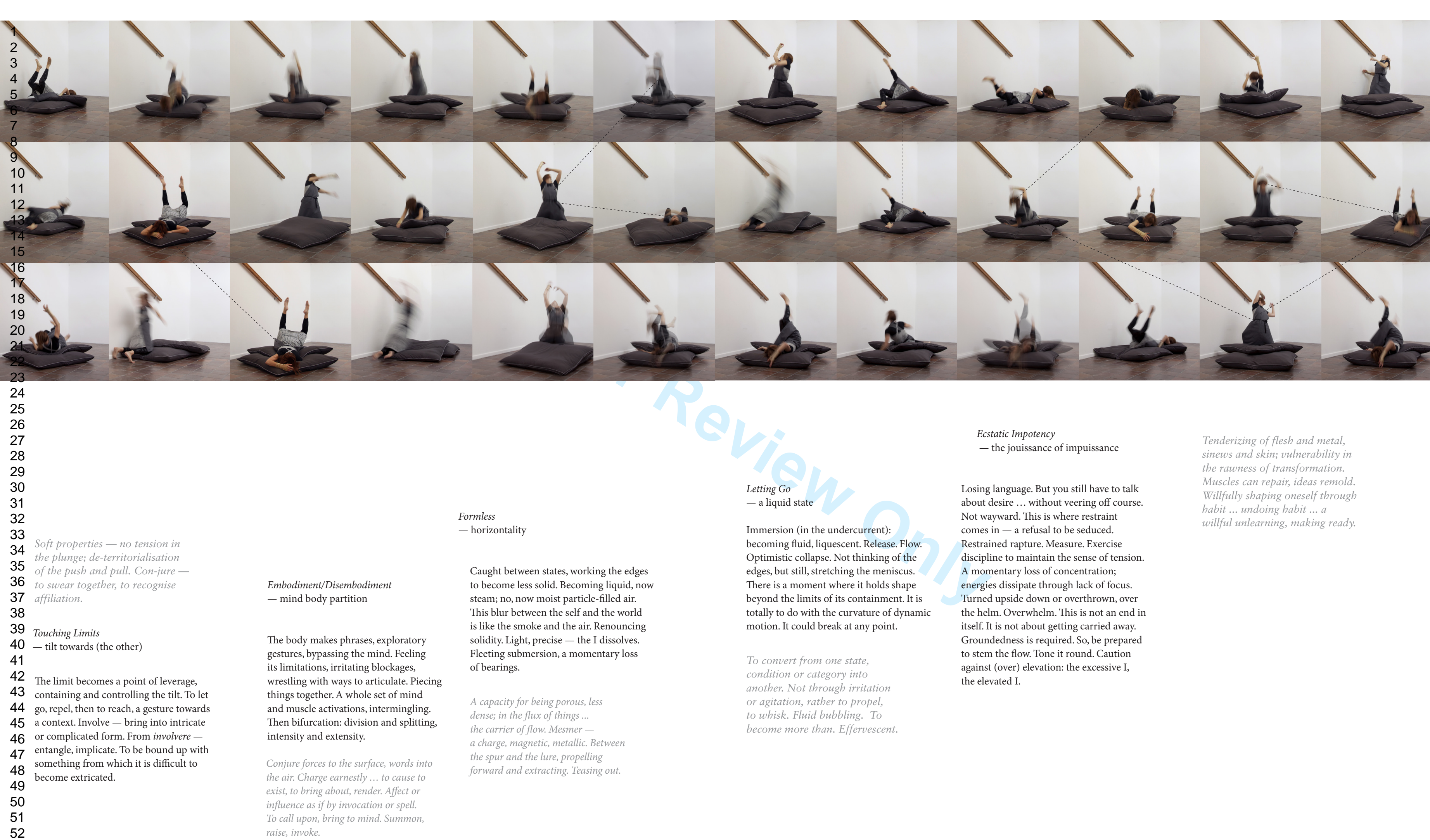


Theatre, Dance and Performance Training

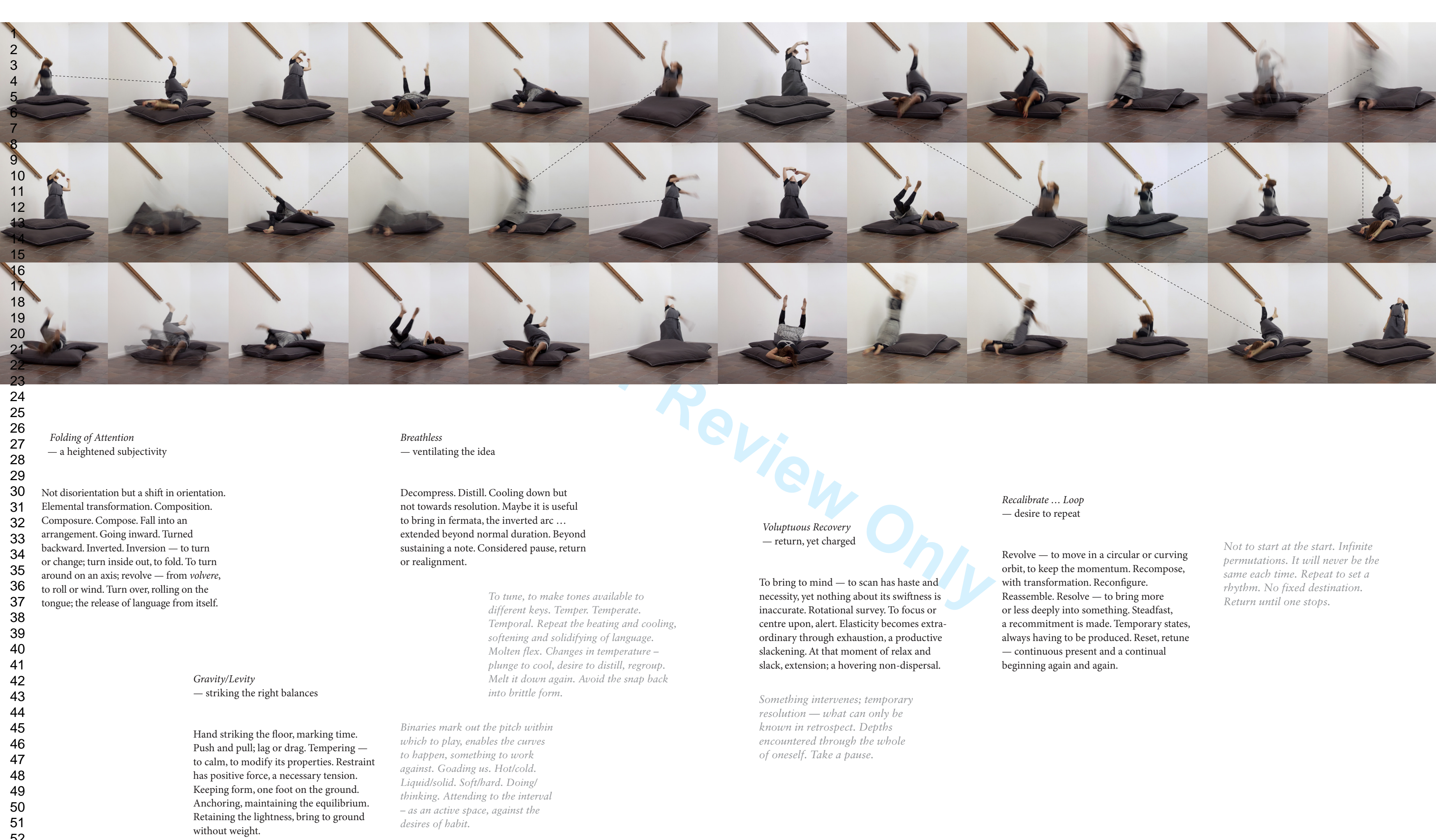


The Italic I - A 16 Stage Lexicon on the Arc of Falling

Emma Cocker and Clare Thornton

The Italic I is a practice-based collaboration between writer-artist Emma Cocker and interdisciplinary artist Clare Thornton that explores the different states of potential made possible through purposefully surrendering to the event of a repeated fall. ${ }^{1}$ Rather than an accidental occurrence encountered by chance, within our artistic investigation falling is apprehended consciously as a training exercise for mind and muscle, tested out in physical, cognitive, and even linguistic terms. Within The Italic I the act of falling is slowed and extended through the use of both lens and language, as a means for attending to its discrete phases or scenes. Central to our performative-poetic enquiry has been the production of an artists' publication (of the same title as our project), comprising photographic performance-documents presented alongside a textual lexicon generated in the 'free-fall' of conversational exchange (Fig. 1). The publication is not conceived as documentation (of a performance), but rather as a performative enactment of our enquiry, an exercise companion. We approach the production of the publication as a form of training in and of itself, requiring a specific physical and conceptual practice undertaken towards building - increasing and deepening - our collaborative capacity. Less a step-by-step manual for instructing another on how to fall, we propose the publication The Italic I as a spur or prompt for cultivating a willfully non-corrective tendency in thought, speech and action, for operating against expectation. 
Fig. 1. Emma Cocker and Clare Thornton, The Italic I, artists' publication. Photographic documentation: Tom Hemming, 2014.

In this article, we present a reworked version of the artists' publication as central pages, as leverage against which to elaborate various concerns arising through our practiceresearch, not least our desire for reframing both the performance document and performance writing as extensions of, rather than distinct from, the process of performance training itself. The acts of doing, thinking and speaking are conceived as inseparable, interrelated components within The Italic I. Image and text operate in nonhierarchical relation, distinct yet inextricably interdependent. Echoing the convention of other performance training manuals, The Italic I consists of both words and photographic stills. However, rather than view these technologies as somehow deficient or delimiting - as incapable of capturing and reflecting the experiential nature of the live event and the moving body in space - we approach lens and language as a form of provocation. ${ }^{2}$ The productive friction - even collaboration - between image and word is apprehended as an exercise in itself; each is considered in receptive relation to the other, where aspiring to articulate becomes part of the impetus for our work. 
The Italic I has evolved gradually over a period of years and remains in progress (supported by an Arts Council Grant 2014 - 2016). We - Cocker and Thornton - had previously 'crossed paths' as contributors within other artistic and curatorial projects; however, our first actual collaboration took place within the context of Fragile Materials, a three-month residency undertaken by Thornton at Aberystwyth Arts Centre (2011). ${ }^{3}$ As part of this residency, Thornton invited Cocker to join her for a week to explore through conversation, drawing-diagramming and explorations of the local landscape, for example the threshold zone where tidal and river waters fold together - shared ideas and overlapping vocabularies around the motifs of folding and falling. Our conversations together eventually developed towards reflection on different tactics through which a sense of self might be pressured towards its limits, the boundary where self/other or self/world begins to fold - for example, through collaboration, through the act of falling. We began to conceive a collaborative framework - involving performance, photography, video, sculptural-material components and poetictheoretical reflection - within which we might further explore active inhabitation of the perceived passivity and impotency often related to the idea of a fall (from the known, normative, certain or stable), interested in how this might be experienced as an ecstatic site (of opportunity) for activating unexpected forms of embodied, tactical knowledge and augmented subjectivity. We have since worked together in the studio for intensive periods of practice-based exploration, primarily within the context of Summer Lodge (2012 - 2015), an annual intensive artistic residency hosted by the Fine Art department at Nottingham Trent University. 
Our first Summer Lodge residency (Summer 2012) comprised a series of speculative studio-based explorations - structured around a set of constructed work-stations including a drawing/conversation table, a diagonal 'falling' support - involving performed falling (Thornton), performative drawing (Cocker) and staged conversational exercises (Cocker and Thornton) (Fig.2 - 4). During this phase, we repeatedly returned to both the drawings and documents made during the live process of falling, as prompts for a dialogue from which we developed the initial working titles or categories of our eventual lexicon.
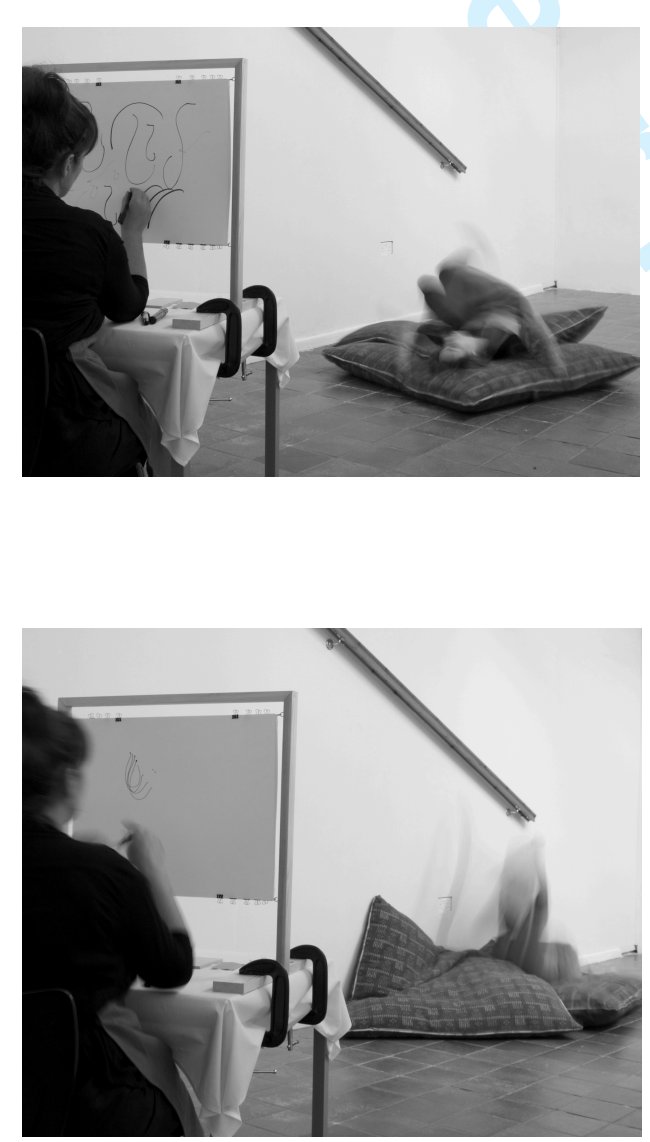


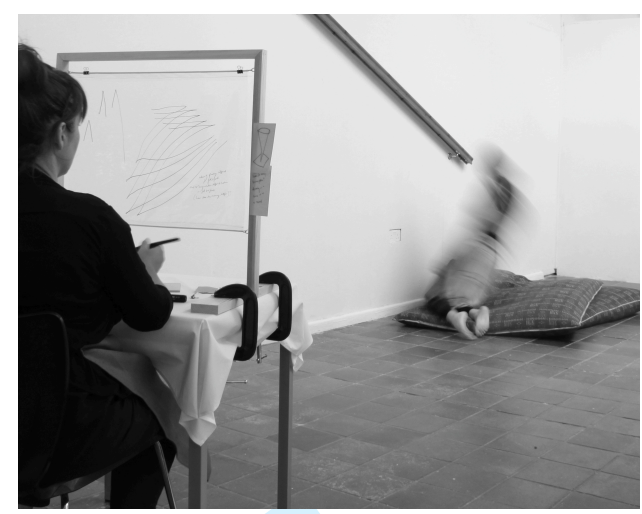

Fig. 2 - 4. Documentation of studio explorations during Summer Lodge exploring performed falling (Thornton) parallel to live drawing/diagramming for reflecting on the fall (Cocker). This specific drawing exercise was undertaken behind an opaque drawing screen, attending only to the sound of the falling. Photographic documentation: Christine Stevens, 2012.

The second residency (Summer 2013) refined and clarified a working methodology that further pressured our own specific (inter)disciplinary backgrounds: Thornton's physical falling (informed by her background in performance and choreography) apprehended through the mediation of the camera (Cocker's background in lens-based practice). During this phase, we began to shift from considering the role of the lens as a means for capturing movement as chronological or sequential frames (the indexical act of witnessing, of being there), towards an interest in the relation between visual documents generated from different falls, and the potential for difference, repetition and even recursion therein (Fig.5 - 6). 
Fig.5 - 6. Emma Cocker and Clare Thornton, The Italic I: Recursive Loop, 2013. Studio explorations during Summer Lodge (2013) exploring repeated falling. A performed fall (Thornton) is documented (by Cocker) at a specific point in its arc, the photographic image is then printed and displayed in the studio. For example, Fig. 5 can be seen on the wall in Fig.6. The fall is repeated, an attempt is made to capture it again at the same point in its arc, whilst also including the photographic document within the same frame. This process is repeated.

The use of photography allowed the fall to be 'slowed down'; the resulting documents lingered over, even returned to out of sequence. We also attended to the differences even discrepancies - between audio and visual documents of the event of falling: if our photographic records captured the body in flight as much as fall (as somewhat aerial, even ethereal) then sound recording attested to its weight and density, the inevitability of gravity, the return of the body thumping to ground. These various documents 
alongside our recollection of the live experience - of falling, of attending with and without lens - were taken as starting points for daily studio conversations, based on a shared conviction in language and reflection as intrinsic to artistic practice. The live performed falling was not formally witnessed by an audience, for our focus addresses the specificity of experience communicable through the use of lens and language, the mediation of performance through its documents (both photographic and textual). ${ }^{4}$ Whilst our enquiry has increasingly explored those forms of performativity emerging between live performance and lens-based mediation, this article focuses on how we have attempted to access and articulate the studio-based exercise of repeated falling through the production of an artists' publication, through a page-based presentation of that experience. ${ }^{5}$

The Summer Lodge residencies (specifically 2012 - 2013) provided a context for exploring the studio as a gymnasium or a testing-ground where a commitment is made to the event of repeated falling in and of itself. In our developing lexicon for reflecting on falling, the initial phases are those of the preparatory, for cultivating the conditions of readiness (of both space and self) and a willingness to surrender to - rather than resist - the event of a fall (see central lexicon pages for details). First - setting up the conditions. There is a ritual element, the crossing into a demarcated zone that has certain affordances, certain architecture or apparatus to work with and against. A charged space poised ready for action; a diagonal support, some means of cushioning the blow. A body falls, over and over, again and again: falling as investigative action. Sense of focus, single purpose - the studio dislocates the fall from narrative cause and effect. It creates a frame - even parenthesis - a zone for testing rather than evading 
risk. Here, the event of falling is conceived as a specific training exercise or live performance-as-experiment where it is entered into electively. However, the purpose of practicing is not towards the perfection of a given move or some future performance. Rather, falling is repeated in a move towards deeper understanding, for becoming more sensitised to the experience, more attuned to its risings and falls, its intensities and durations. Within our investigation, preparation and indeed training are not undertaken for 'reaching towards' a specific endpoint or telos but as a mode of performance making in their own right - training-as rather than before performance, autotelic.

Whilst The Italic I has been staged as exhibition-performance (for example, at Project Space Plus, Lincoln, November 2014), a core strand of our enquiry has involved the attempt to articulate the experience of falling as experience through a page-based investigation. Our intent has not been to produce a manual on or about falling, identifying categories of fall (a trip, slip, drop, stumble, crumple, downward slide), nor diagramming the anatomy of a fall as such. Not so much a how to fall, as a how is falling. A fall is a period of passage, rather than a series of steps or postures that can be isolated, observed. Whilst generating the photographic imagery, it became clear that we were not interested in producing a chronological record, a step-by-step guide. Neither instructive nor corrective, the lens facilitates an encounter with performance that is not to do with the clarity or resolution of a given move. Through the process of photographing the event of falling we realised that our aim was less about fixing the visible or extensive moves of movement but rather one of seeking a visual vocabulary for articulating the register of intensity or sensation within the event of falling, the 
force of what-cannot-always-be-seen. We are not concerned with capturing what the choreography of a fall looks like, as much as trying to reflect on its interiority (the feeling-in-falling, the nature of its phases as lived experience). We ask: how might we articulate the felt experience, the qualities of passage and the temporal dimension of falling? Through what means might we communicate falling's flows and forces, its speeds and durations, both visible and invisible? ${ }^{6}$

Over and over, a body falls, a lens acts as witness. The photographic frame reinforces the frame of the studio, further dislocating the fall from everyday narratives of cause and effect. Moreover, the technology of the camera enables a form of seeing differently - both faster and slower - to the rate that the eye can comprehend. However, our photographs of falling - even those that show the blur of movement's passing - still capture the fall's form, slice of falling rendered static, image as a representation of timeas-space. Whilst the photographic still might be deemed insufficient for reflecting the lived nature of movement, least of all the passage of a fall, the sequencing or succession of images has the potential to articulate a quality of experience not even visible in the live performance itself. Within our artists' publication, we have adopted a nonchronological arrangement of images presented as an extended grid, resisting or troubling the normative chronology often used for presenting the body in movement. This visual organisation arose through practical experiments in the studio initially using medium $(6 \mathrm{~cm} \times 6 \mathrm{~cm})$ format analogue photography, with the photographic focus one of attending to the same point in the arc of falling, over and over again. Consecutive images on the resulting 'contact sheet' appeared as sequential in time through their visual similarity, though were actually from different falls separated by seconds, even 
minutes. We further explored this sense of visual proximity combined with temporal separation using digital photography as a way of enabling us to record, print and return the image to the studio within a short production cycle (see Fig.5 - 6). These temporal discrepancies and anomalies within the document echoed our interest in Catherine Clément's reflections on the fainting subject in Syncope: The Philosophy of Rapture where she states, "Suddenly time falters. First, the head spins, overcome with a slight vertigo ... the earth gives way and disappears, one sinks back, goes away (but) where does one go?"7 Falling experienced as both temporal flux but also as discontinuity, where what we encounter - to draw on Erin Manning's writing - "is a composition of holes (intervals) and wholes (pure experience, duration) that together create a field of forces around which perception takes form". ${ }^{8}$

Willful disruption of the unfolding logic of a step-by-step guide, our sequences of falling refuse to be comprehended in strictly linear terms, instead aspiring towards multidirectional reading. Unexpected rhythms emerge in the broken beat of abbreviated action. The unsettled, even syncopated, configuration was used as a means for inviting the viewer/reader/user's attention to become scattered or distracted in its search for connections between one frame and another, where - as with the live experience of a repeated fall - the sense of sequential logic within falling becomes difficult to discern. ${ }^{9}$ Since a single still image cannot articulate the moving of movement, we offer a plethora of fragments, disrupted durations and passages. Our interest lies less in the articulation of discrete postures or positions, but rather in the intervals and ambiguities between, in the potential of a movement's repetition, permutation, deviation. In other contexts, we have explored the reanimation of the photographic still, examining the specificity of 
those expanded - even virtual - modalities of performance and performativity produced at the threshold where live and lens meet. ${ }^{10}$ However, in developing the artists' publication itself, the critical issue of what remains unsaid or unspeakable within the photographic document provided the very conditions for dialogue.

Within The Italic I, we approach the act of conversation as means for reflecting on practice, but also as a generative or productive practice in and of itself. Conversation is considered as a mode of writing without writing, the method through which we have attempted to generate a working vocabulary for articulating our shared enquiry. During our conversations we have addressed the 'becoming' of falling (to fall - a verb, a process-oriented operation), reflecting on the interior complexity of falling - the capacities, temporalities and affective dimension therein - which visual expression can only hint towards. Together in conversation we seek to practice linguistic or even cognitive falls, searching for a language adequate to the task of articulating the experience of falling through falling, produced simultaneously to the process that it strives to describe. Akin to the body repeatedly falling, language can be generated from within fall-like circumstances, produced from the dialogic free-fall of collaborative exchange. In the live-ness of conversation, words can slip and spill into existence, sentences unfurl without knowing fully the direction they will take. The shape of a thought can be conjured in the live event of its utterance, verbalised at the point of thinking leaning into the unknown. Significantly, the cadence or rhythmic pacing - the pitch and intonation pattern, the speech tempo - of conversation is often one of rising and falling, dipping and peaking. Conversation's rhythm can be shaped by heightened inflection, excited acceleration, pauses and hesitation. Deliberation. Syncopation. 
Abbreviation. Words dropped. Omissions. Repetitions. Sentence incompletion.

Disregard for punctuation. Hurried utterance. Syllabic glides and slurs.

Moreover, words themselves can be pressured until they begin to arc and fold, pushed to excess then contracted. Over and over, turned up and inside out, language can be rolled around in the mouth until it starts to yield or give. Vocabularies can be physically grappled with, or rather apprehended through an active un-grappling, the tension and release of terms from their habitual use and function, retrieval of meanings lost and forgotten through etymological play. We ask: what happens if talking about practice is no longer an event of instruction or explication, but performed in the same key as doing. Within The Italic I, the discourse and dialogue on the process of training - the exercise of repeated falling - not only steer and shape our perception of that training but are conceived also as an extension of its affect. We aim towards a condition of exhaustion and elasticity in word and thought, a form of collaborative conversation with a shared arc to that of falling, requiring a parallel stepping off or away from the stability of fixed subjectivities and positions towards the fluid process of co-production, intermingling of one another's word and thought. As Debra Hawhee states, the Ancient Greek term for "Mingling (summisgomena) comes from the middle verb summignumi, which may be translated as 'mix together, comingle', 'join forces' or 'form an alliance' ... 'meet, as in communicate' and 'meet in a close fight'." ${ }^{11}$ Echoing this definition, ours is the productive struggle of forces joined in live endeavour - a process of warming up, a commitment made, letting go, a liquid state, tilt towards (the other). Sentences form tentatively in the gaps as one voice falls or falters into another ... as one thought collapses, another starts to rise. 
Like our staging of the fall, our conversations are framed, undertaken as a specific exercise within a time-bound period allocated only for this purpose (usually between one and three hours). We converse until it no longer feels generative, until we need to stop. Whilst dialogue has taken place directly following the live performance itself, we have also met some time after the event using the performance document - and also the initial lexicon titles - as a training spur, a device for provoking exchange. The lexicon, an exercise in naming - each name a call through which to conjure a corresponding language, to summon up, invoke. At times, choice references - from art, literature, philosophy, theory - might be interjected as lubrication or provocation, a little seasoning perhaps, should dialogue lose its steam, its vitality ebb. ${ }^{12}$ Here too, the performance document operates as the ground against which we temper the ecstatic effervescence of our imaginative lines of flight. Our intent is not towards a technical or biomechanical analysis of the movement evidenced within the image. Rather, we attend to the document for its very gravity, its density; as a necessary anchor point for tethering our ideas should they become too wayward, over-elevated, tend to veer off course.

Whilst often perceived in opposition or tension, within The Italic I the relation between performance, document and language is approached as a productive sparring, a nonantagonistic point of encounter absent of competition for mastery. Speaking is a mode of doing; conversation is action. Indeed, as Yvonne Rainer advocates, "the mind is a muscle" ${ }^{13}$ Certainly, it can be difficult to shape experience into words, language can sometimes seem too stiff or rigid, like the body it also needs to be stretched and flexed. 
Within The Italic I, the perceived difficulty of 'putting into words' is transformed from problem into provocation. We recognise a desire for ease as the normative tendency; moreover, how it creates a parallel settling for tongue-tied-ness. We ask: why would one not want to stretch, cultivate one's agility in speech as much as action, nurture one's endurance for working out with words? So, how might language be exercised akin to lungs and limbs? Focused exercise or training might well require a sparring partner: we conceive our collaborative dialogues in these terms, as time-bound 'work-outs' in which we make a commitment to wrestling with language, with each other's words.

Conversational sparring enables a form of thinking and articulation beyond what is often conceivable on one's own. Sparring akin to spurring on; to spur - to goad or urge to action or achievement, to impel, inspire, instigate. Within our dialogic sparring, distinct refusal of the training convention of master/mastered; we each are neither follower nor leader. Instead, spurring partners - together creating the stimulus, incentive, inducement, the necessary push or pull. The form and content of The Italic I emerges through us wrestling with the idea of what it is to collaborate; moreover, through the wrestle between the experience of liveness and the mediation of the lens, between what can be seen and what can be said. Wrestling not to control or compete: not to win but to be thrown, to be pleasurably imbalanced, sent side-ways. We seek a language not already rehearsed and in waiting, rather co-produced on the spur of the moment. Within The Italic I, conversation is conceived as the site and the material for the construction of inter-subjective and immanent modes of linguistic sense making, initiated in the hope of finding a language but without anticipating it in advance. ${ }^{14}$ Conversation becomes a means for drawing, forcing - even forging - language into being, a practice of poesis as much as of poetics. 
Within our process, meaning does not exist prior to the event of utterance, but rather is discovered (often retrospectively) through a dialogic process. Our conversation is staged, recorded, transcribed and then edited. The specific rhythm of conversation - its risings and falls - can produce a different shape and texture of textual articulation compared to that of conventional writing. The process of generating the vocabulary for The Italic I publication has involved thousands of transcribed words from hours of recorded conversation gradually distilled (over a period of years) towards a lexicon and emergent poetics for articulating the various phases of the fall. By extracting phrases as well as singular words, our intent was to retain something of our conversation's original cadence, alongside the potential for a slip or switch in tense, inflection, imperative or mood. The act of concentrating the extended conversational transcripts towards dense segments of prose-poetry has allowed us to linger in and extend the phases of falling in ways that the photographs did not fully allow, facilitating a return to those states not possible to articulate in the action itself. Our lexicon comprises sixteen overlapping categories: Testing (the) ground - setting up the conditions; Opening attempt - warming and flexing; Entering the arc - trust, twist, torque; A commitment made - working against impulse; Voluntary vertigo - ilinx, inclination; Becoming diagonal - the italic I; Touching limits - tilt towards (the other); Embodiment/disembodiment - mind body partition; Formless - horizontality; Letting go - a liquid state; Ecstatic impotency - the jouissance of impuissance; Folding of attention - a heightened subjectivity; Gravity/levity - striking the right balances; Breathless ventilating the idea; Voluptuous recovery - return, yet charged; Recalibrate ... loop - desire to repeat. What follows is a reworked version of The Italic I presented as artists' pages, 
including new annotations not present in the original artists' publication, through which we indicate a possible direction or training use, a potential application for our guide.

\section{PDF - The Italic I Artists' pages inserted here}

So if not intended as a guide for training another on how to fall, then what is trained through the production and provocation of The Italic I? Less concerned with teaching a repertoire of moves or postures, our intent is rather more towards addressing the capacities and qualities produced through the event of elective falling. Through practice, we examine how repeated falling - physically and perhaps also linguistically might have transformative, even alchemical, potential; for converting the initial experience of humiliation towards humility; fallibility towards vulnerability; impotency towards a productive, potent force. Whilst falling requires some loss of power and control, with practice the passivity and apparent weakness often associated therein can be converted into a potential means of strength. However, we are not affiliated with cognitive-behavioural models of self-improvement or development, the corrective disciplining of body and mind to inoculate against or neutralise the fear of falling. The intent is not to become desensitised to the experience of a fall, if this means becoming resistant or immune to its charge. Rather, we recognise the benefits of periodic imbalance, the dynamic potential of the diagonal as deviation from the regime of verticality, alternative to the privileging of uprightness, the pressure of keeping one's head aloft, held high. Here, a shift is practiced from the valuing of rigour and erectness in thought and in form, towards advocating the qualities of elasticity, flexibility, agility, 
even litheness of intelligence (both of body and of mind). The resolve required for repeatedly falling is of a commitment made to working against impulse, not the quest for the fixity of conclusion or solution. Indeed, falling involves the dynamic of leaning into or even surrendering to the unknown, a stepping off or away from stability or certainty, relinquishing the sense of having one's feet firmly on the ground. It requires receptivity to energies outside of one's control, a giving in or over to the charge of forces other than one's own, including gravity's pull. Yet to electively fall is not to be defeated by gravity's law but rather to experimentally and experientially test or try its logic; moreover, to feel the liberation of momentary flight and groundlessness that unexpectedly arises through letting go of - even disobeying - the habit that would have us upright, to trip this tendency up.

Akin to other investigations around the art of falling, we approach the event of a fall as an augmentative and affirmative act. As Moshe Feldenkrais states, "Most people learn to maintain upright carriage for considerable periods and never further their adjustment to gravitation beyond this infantile state ... by teaching the art of falling properly, we further the person's maturity towards a more adult independence of the gravitational force.${ }^{15}$ Moreover, falling also involves the active practice of seeking independence from the force of expectation and convention, the cultivation of a noncorrective tendency willing to yield to the fall rather than resist. Indeed, the active practice of falling might require an un-schooling of mind and muscle, training against training: through falling, forging a different relationship to movement, to being and behaving. In these terms, we conceive The Italic I as an un-training guide, as a tool or device through which to practice a capacity and indeed the stamina for working against 
habit and reaction, against the logic of certain kinds of cultural conditioning

(specifically concerned with the preservation of an assured and stabilised sense of the self, the individualising tendency of contemporary neoliberal life).

Through repeated falling, a shift or conversion is practiced from self-consciousness (the excessive - at times embarrassing - hyper-awareness of the illusory distinction or apartness of oneself from other things) towards self-consciousness (heightened awareness enabling the expansion and porosity of the self, the desirable blurring between selfother/self-world). The Italic I - I tilted diagonally in the gesture of fall, a leaning or inclination towards the unknown (through artistic investigation), towards the other (through collaboration). It is in this sense perhaps, that we might consider the practice of elective falling as an ethico-aesthetic 'practice of the self', a means by which the sense of I folds back upon itself towards affecting a process of self-transformation. In his writing on the 'practices of the self' or 'arts of existence' (techne tou biou), Michel Foucault reflects on "those intentional and voluntary actions by which men not only set themselves rules of conduct, but also seek to transform themselves, to change themselves in their singular being, and to make their life into an oeuvre that carries certain aesthetic values and meets certain stylistic criteria”. ${ }^{16}$ Drawing reference from the practices of Ancient Greece, he argues how life can be conceived as a malleable material that can be molded, approached as aesthetic production as if it were 'a work of art'. ${ }^{17}$ The Ancient Greeks developed a complex interlocking system of preparatory training and reflexive exercises (askēsis), for testing mind and body through both meletē (meditations or imagined situations, 'practices in thought') and gumnazein or exercitatio (the training of oneself in actual situations). Elaborating the function of the 
gymnasium, Foucault argues how the terms gumnazein or gumnazesthai - which mean 'to practice', 'to train' - related closely to the idea of a "practice or training in real life". ${ }^{18}$ He states: "Gumnazein actually involves being present in a real situation, either that one has artificially called for and organised, or that one encounters in life and in which one tries out what one is doing". 19

Less akin to the contemporary 'work-out' culture intent on shaping the body towards a particular normative target or goal, The Italic I could be conceived as a contemporary manifestation of the Ancient gymnasium, a charged site for practicing the 'arts of existence', for the willful re-calibration of body and mind, action and thought. We consider the studio-as-gymnasium as a critical context for isolating the fall from external narrative, reframing it as an exercise - even exercitatio or gumnazein - through which to glean knowledge of and from within this experience. Debra Hawhee examines how 'bodily knowledge' or the 'arts of hexis' (an intelligence of the body) was cultivated in the classical gymnasium through various programmes for "shaping a compounded self - body and mind - with training in gymnastics and discourse" ${ }^{20}$ For Hawhee, the gymnasium sought to provide a "unified training in athletics and oratory ... a programme for shaping an entire self" ${ }^{21}$, with the aim of producing a "receptive, open body ... exhibiting an intense yet open stance, a body that radiates readiness". ${ }^{22}$ She further argues that within this model, "bodily disposition is inextricably tied to thought - transformation of one inevitably produced a transformation in the other". ${ }^{23}$ The Italic I similarly attempts a fusion of athletic, intellectual and rhetorical action, the parallel and reciprocal working out of both language and limb. 
So what kind of person is produced through the recuperation of this model of training? Reflecting Hawhee's assertion that, "the gymnasia were recognised sites for the production of citizen subjects", we conceive our training as a means through which to 'practice the self'; moreover, for cultivating the potential of an agile and critical mode of subjectivity or citizenship, capable of withstanding the indeterminacies and uncertainties that are experienced as normative within the conditions of our contemporary precarious life. ${ }^{24}$ Within The Italic I, the studio-as-gymnasium becomes a site for practicing falling, apprehended as a form of training for behaving otherwise, for nurturing a willful non-corrective tendency, the potential of a radically resistant 'second nature'. Hawhee uses the term phusiopoiesis to describe the Ancient 'arts of training' and preparation aimed towards the "production of one's own nature", where "the nature (phusis) of the body ... can be rendered malleable, made (poiei) into something else". ${ }^{25}$ She argues how the process of training was undertaken as an active undoing of certain habits in order to cultivate habits new: "(t)hrough habit, therefore, a 'second nature' emerges". ${ }^{26}$ Hawhee notes the shared vocabulary between the reshaping of the self in the gymnasium and the craftsman's working of iron, "The first step in shaping iron or athletes is to rarify the material, to make it thin or porous, less dense". ${ }^{27}$

Within our own experience, we recognise this phusiopoietic process of transformation in the repeated rendering malleable of our material, our situation, ourselves: we practice falling and also collaboration in a manner that both rarifies and tempers. Rarify refine, a practice for becoming open and porous to the other, to the experience unfolding. At times, we add levity for aeration, to avoid becoming too dense. Parallel 
practice of tempering, making temperate - to modify or import the qualities of strength, resilience and elasticity through a process of heating and cooling, else through the addition, mix or mingling of conducive materials. To temper - to strengthen through experience, toughen, yet also to soften or tone down. Our lexicon refers to this process of repeated heating and cooling, softening and solidifying. Moreover, we note that 'to temper' also means to tune, a process of recalibration for making tones available in different keys and tonalities. We ask: how might body and mind also be tuned to a greater range or reach? What other frequencies - even octaves - of being and behaving might be practiced? Significantly, as Hawhee stresses, the process of phusiopoiesis - the practice of the self (differently) through the production of one's nature - "cannot be articulated as 'steps' for improvement, but rather emerges among a variety of forces" ${ }^{28}$ We understand this through our own investigation, where the knowledge generated is not 'bankable' or transferable - to be taught through transmission from expert to novice - but rather operates as a power or force that must be actively embodied, cultivated in and through application and practice. In this sense, it could be conceived more as knowledge in actu. This is not to say that knowledge or power remains a latent force that is activated through action, but rather as Alain Pottage argues, "that power exists only en acte, or in actu, (which) is to say - in language closer to Spinoza ... that it 'is' only in the process of its exercise". ${ }^{29}$

At one level, The Italic I comprises a bespoke training programme that we have developed specifically for the purposes of sparring together, a means through which to push ourselves through thought and action. Arguably, the artists' publication The Italic I is a record of its own making, where the production itself was conceived as a form of 
training or sparring, for activating and then reflecting on the knowledges and capacities produced through a process of falling in both physical and linguistic terms. The publication itself is a single iteration of our findings, where word and image momentarily coalesce towards a sharable form; a concertina structure where the physical process of its unfolding (by the reader) hints towards a potential for both expansion and contraction (Fig.7). Moreover, the design has the capacity to wrap around to form a circular structure, indicating the desirability of the loop, of repeated action within our model. The Italic I is not considered resolved, instead the provocation for future sparring, a new spur against which we continue to train. The training is completed when it is exhausted, no longer generative. Reset, retune - a continual beginning again and again.

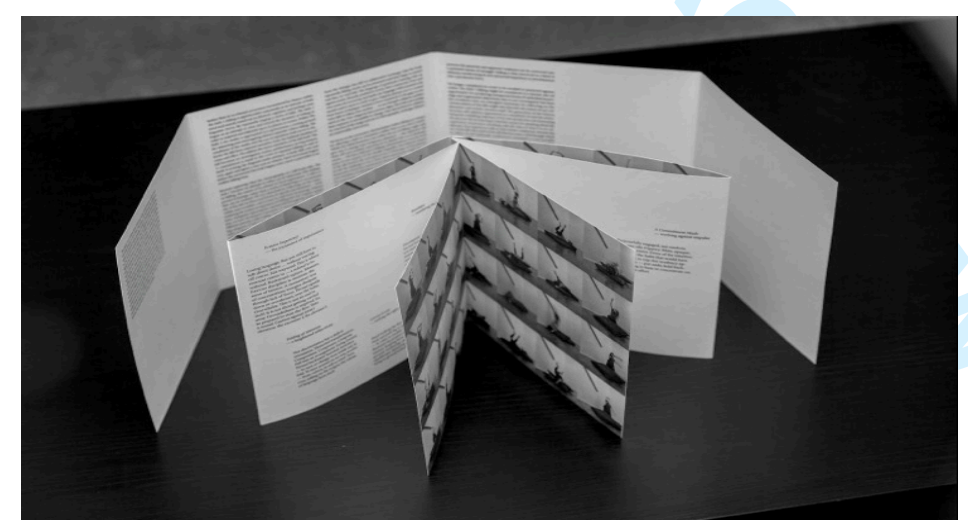

Fig. 7. Emma Cocker and Clare Thornton, The Italic I, artists' publication. Photographic documentation: Tom Hemming, 2014.

The published artifact, The Italic I, has provided physicality to our findings; a point of shared reference for handling, for working on (through notes and annotations) as much as with. Within recent conversational sparring, we have reflected further on the 
capacities and properties cultivated through falling, which in this article we present as a second stratum of annotation interweaving the original lexicon. Additionally, we have come to realise that the arc itself could be joined at different entry points depending on one's experience. At times, the phases of preparation or warm-up might become compressed or else extended; on occasion the order itself might require unsettling, disruption, rearrangement. Through sustained engagement, we recognise that our lexicon categories have porous edges, they leak and overlap, their sequence is susceptible to change. There is an intended playfulness of application. Whilst The Italic I is not intended as a step-by-step guide, its photographic documents could still be taken as an open score, a constellation of possibilities through which to plot and perform new choreographies (for example, by interpreting the diagrammatic annotations visible on the lexicon pages). In the seam between one image and the next we invite the imagining of infinite possibilities; durational experience conceived as simultaneously indivisible, yet endlessly divisible. We ask: how far could the sequence expand between one micromovement and another? Extend the duration. Elaborate the moves between. Activate the intervals. Test unexpected ways for moving from one position to another. Practice alternative routes between 'here' and 'there', as micro-training for the practice of the self otherwise.

Whilst The Italic I addresses issues of conduct - personal behaviour, ways of acting in the world - its intent is not corrective, instructive or pedagogic, but perhaps rather conductive, concerned with a transfer or flow of energy, the desire for (ex)change. The artists' publication is an attempt to share findings from our training, from our research; however, we seek to transmit a set of possibilities without prescribing the form that 
these should take. Ours is not a technical guide. Transmit - to spread, to convey or pass along an impulse, force, motion, or perhaps even contagion. We hope our training materials are able to pass a current, send a charge, to spur another to spar. Indeed, whilst the photographic documents within our publication explicitly refer to the act of repeated falling, the nature of our lexicon is purposefully left open, avoiding direct description of the physical event of a fall. We conceive an affiliation with other practices engaged in the cultivation of capacity and attention, the potential of a noncorrective or non-normative impulse: acts of extended listening, the practice of stillness, collaboration itself. In one sense, our model invites a laterality of application: the quality of micro-attention activated within The Italic I could be applied to other situations or actions, other contexts.

Key to our investigation has been the revelation that our emergent lexicon for reflecting on falling might also describe the nature of our collaborative and artistic practice. In one sense, the arc of falling shares a similar 'movement' to that of the creative process, involving an elective stepping off from what is known and certain towards the as-yetunknown. Here then, the lexicon becomes self-reflexive, approached as a manifesto of sorts for articulating the unfolding trajectory of its own production. Within The Italic I, the motif of the fall emerges as a foil for reflecting on the often undisclosed, unnamed, or even invisible tipping points between thinking and action within artistic endeavour, shedding light on the process of artistic collaboration itself and the making of meaning within creative labour. For those who desire the clarity of instruction, The Italic I might appear as a somewhat misguiding training device on how to fall. As such, we end with a final caveat so as to prevent misinterpretation, inviting our potential reader/user to be 
receptive to our lateral approach, tuned into another frequency of meaning emerging in the intervals, gaps and grey areas between. Drawing on the writing of Luce Irigaray we call our reader to attend differently, "in order to hear 'an other' meaning which is constantly in the process of weaving itself, at the same time ceaselessly embracing words and yet casting them off to avoid becoming fixed, immobilised" ${ }^{30}$

1 Parallel investigations include Emma Cocker and Clare Thornton, 'The Italic I: Towards a Lexicon for Reflecting on the Arc of Falling', in Fall Narratives (eds.) Zohar Hadromi-Allouche and Áine Larkin (Ashgate Publishing, 2016), ‘The Italic I: Studio as Gymnasium', in drain, Athleticism, (2015) and 'The Italic I: Between Liveness and the Lens', conference paper (and forthcoming article), The Alternative Document (University of Lincoln, 2016).

2 We affiliate with those thinkers who explore the complex relation between notions of live-ness and the lens as an active, experimental site of practice, for example, Bridget Crone, The Sensible Stage: Staging and the Moving Image, (Picture This/Plenty Projects, 2012); Alice Maude-Roxby, Live Art on Camera: Performance and Photography, (John Hansard Gallery, 2008), Erin Manning, Relationscapes: Movement, Art, Philosophy, (MIT Press, 2012); Rebecca Schneider, Performing Remains, (Routledge, 2011).

3 We - Cocker and Thornton - first met in a cave in the Avon Valley for Women with Weapons, a bow and arrow making workshop led by Girl Gang as part of the Summer of Dissent, curated by the artist-collective Plan 9, Bristol (2009). Our second encounter was during Urban Retreat a series of public art commissions, activities and events (curated by artist Sophie Mellor) for exploring the marginal landscape in Barrow-in-Furness, Cumbria (2010). 
$4 \quad$ Independently of this collaboration, we have both contributed to the research project Performing Documents, which explores the problems and potential of performance and its documents. Performing Documents is funded by the AHRC and hosted by University of Bristol, in partnership with University of Exeter, Arnolfini and In Between Time.

$5 \quad$ See for example, Cocker and Thornton, 'The Italic I: Between Liveness and the Lens', 2016.

6 This line of argumentation is developed further in Cocker and Thornton, 'The Italic I: Towards a Lexicon for Reflecting on the Arc of Falling', drawing on the theoretical work of Erin Manning and Henri Bergson.

7 Catherine Clément, Syncope: The Philosophy of Rapture, (Minneapolis, University of Minnesota Press, 1994), p.1.

$8 \quad$ Erin Manning, Relationscapes: Movement, Art, Philosophy, (Cambridge, Mass: MIT Press, 2009), p.85.

$9 \quad$ We developed the artists' publication itself during Summer Lodge (2014), providing a context for further testing and gaining feedback on our visual proposition in dialogue with other residency participants.

10 For example, within the exhibition The Italic I at Project Space Plus, Lincoln (2014) we worked with analogue slide-projector technology to explore the relation between still and moving image.

11 Debra Hawhee, Bodily Arts: Rhetoric and Athletics in Ancient Greece, (University of Texas Press, Austin, 2004), p.90.

12 For example, from literature (Italo Calvino, Six Memos for the Next Millennium, Penguin Modern Classics, 2009; Simone Weil, Gravity and Grace, Routledge, 2002; and Gertrude Stein, Lectures in America, Virago, 1988) to philosophy (including Bergson, Deleuze, Foucault), to exhibition catalogues such as Presentness is Grace: Experiencing the Suspended Moment, (Arnofini, 2001). 
13 For more on Yvonne Rainer's The Mind is a Muscle (1966) see Catherine Wood, Yvonne Rainer: the mind is a muscle, (London, Afterall, 2007).

14 The method of 'conversation-as-material' used within The Italic I (and other collaborative projects) is explored in the forthcoming book chapter by Cocker, 'Writing without Writing: Conversation as Material', The Creative Critic: Writing As/About Practice, (eds.) Katja Hilevaara and Emily Orley (Routledge, 2017).

15 Moshe Feldenkrais, Higher Judo-Ground Work, (London and New York, Frederick Warne and Co.,1952), pp.19 - 20. See also Feldenkrais, Body and Mature Behaviour: A Study of Anxiety, Sex, Gravitation and Learning, (London: Routledge, 1949). More recent elaborations of falling as a critical and affirmative act include On Falling, eds. Emilyn Claid \& Ric Allsopp, Performance Research, Issue 18, No. 4, Routledge, 2013 and Falling, Kristen Kreider and James O'Leary, (London: Copy Press, 2015).

16 Michel Foucault, 'Introduction', in The Use of Pleasure. The History of Sexuality: Volume Two. (trans.) R. Hurley, (Harmondsworth, Middlesex: Penguin, 1992/1984), pp.10 11.

$17 \quad$ Foucault, 1992/1984, p.27.

18 Foucault, The Hermeneutics of the Subject, Lectures at the College de France 1981 - 1982. (Picador, New York, 2001), pp.425 - 46.

$19 \quad$ Foucault, 2001, p.425.

$20 \quad$ Hawhee, 2004, p.5.

$21 \quad$ Hawhee, 2004, p.6.

$22 \quad$ Hawhee, 2004, p.76.

$23 \quad$ Hawhee, 2004, p.58.

24 Hawhee, 2004, p.112. Indeed, Hito Steyerl argues that the state of 'ungroundedness' or 'freefall' might well be conceived as characteristic of our contemporary experience, in 'In Free Fall: A Thought Experiment on Vertical Perspective', The wretched of the screen, (Berlin: Sternberg Press, 2012), p.13. 
25 Hawhee, 2004, p.12. Hawhee draws on the term 'phusiopoiei' which she states "fuses two critical concepts" phusis, or nature, and poieō, commonly known to mean 'make or do', 'produce' or 'create'.

$26 \quad$ Hawhee, 2004, p.95.

$27 \quad$ Hawhee, 2004, p.92.

28 Hawhee, 2004, p.99.

29 Alain Pottage, 'Power as an art of contingency: Luhmann, Deleuze, Foucault' in Economy and Society, Volume 27, Issue 1, 1998, p.22.

30 Luce Irigaray, 'This Sex Which is Not One', New French Feminisms, eds. Elaine Marks and Isabelle de Courtivron, (University of Massachusetts Press, Massachusetts, 1980), p.103. Originally published as Ce sexe qui n'en est pas un (Minuit, 1977) 